\title{
Sensor Monitoring of Physical Activity to Improve Glucose Management in Diabetic Patients: A Review
}

\author{
Sandrine Ding ${ }^{1, *}$ and Michael Schumacher ${ }^{2}$ \\ 1 HESAV, University of Applied Sciences and Arts Western Switzerland (HES-SO), Av. Beaumont 21, \\ Lausanne 1011, Switzerland \\ 2 Institute of Information Systems, University of Applied Sciences and Arts Western Switzerland (HES-SO), \\ Techno-Pôle 3, Sierre 3960, Switzerland; michael.schumacher@hevs.ch \\ * Correspondence: sandrine.ding@hesav.ch; Tel.: +41-21-316-8096
}

Academic Editors: Steffen Leonhardt and Daniel Teichmann

Received: 17 February 2016; Accepted: 21 April 2016; Published: 23 April 2016

\begin{abstract}
Diabetic individuals need to tightly control their blood glucose concentration. Several methods have been developed for this purpose, such as the finger-prick or continuous glucose monitoring systems (CGMs). However, these methods present the disadvantage of being invasive. Moreover, CGMs have limited accuracy, notably to detect hypoglycemia. It is also known that physical exercise, and even daily activity, disrupt glucose dynamics and can generate problems with blood glucose regulation during and after exercise. In order to deal with these challenges, devices for monitoring patients' physical activity are currently under development. This review focuses on non-invasive sensors using physiological parameters related to physical exercise that were used to improve glucose monitoring in type 1 diabetes (T1DM) patients. These devices are promising for diabetes management. Indeed they permit to estimate glucose concentration either based solely on physical activity parameters or in conjunction with CGM or non-invasive CGM (NI-CGM) systems. In these last cases, the vital signals are used to modulate glucose estimations provided by the CGM and NI-CGM devices. Finally, this review indicates possible limitations of these new biosensors and outlines directions for future technologic developments.
\end{abstract}

Keywords: diabetes; T1DM; exercise; sensor; physiological parameters; vital signs; blood glucose monitoring; ECG; accelerometer; algorithm

\section{Introduction}

The careful control of glucose concentration is important for diabetic patients. This is particularly true for patients with type 1 diabetes mellitus (T1DM), where glucose monitoring reduces the risk of hypoglycemia, of cardiovascular disease with microvascular and macrovascular problems and of neurological abnormalities [1,2]. Controlling blood sugar also prevents patient death [2,3], which could result from loss of consciousness and heart failure. Glucose measurements are traditionally performed by skin punctures regularly throughout the day. However this method is invasive and results in pain to the patient. It is also well established that the finger-prick method affects patient compliance with glucose measurements [4].

Continuous glucose monitoring devices (CGMs) were developed to infer blood glucose levels in real-time, based on measurements of interstitial fluid glucose concentrations. They constitute point-of-care tests [5] that have enabled some improvements in the self-management of diabetes with reduced hypoglycemia and increased time spent in euglycemia [6-8]. However, these benefits are more evident in patients with poorly controlled diabetes who have recently used an insulin pump, in combination with the CGM [9]. More generally, the devices still present a number of limitations. First, the accuracy and reliability of CGMs are limited [3,10,11], notably during hypoglycemia [12]. 
As a consequence, the devices cannot fully replace the finger-stick monitoring but are better suited to complement it. Second, these systems involve the use of cannula inserted in the subcutaneous tissue of the abdomen and are accordingly still invasive.

A number of technologies have been proposed for noninvasively estimating blood glucose concentration. Termed "minimally invasive CGM" or "non-invasive continuous glucose monitoring" (NI-CGM), they were created with the hope of generating more regular, or even real-time, glucose measurements and thus allowing a more efficient self-monitoring. These technologies exploit the changes in the chemical and physical tissues properties caused by the presence of glucose molecules. These changes can be detected based on optical, chemical or electrical phenomena, for example via Raman spectroscopy, fluorescence technology [13], optical coherence tomography [14,15], optical polarimetry or reverse iontophoresis in the case of the Glucowatch Biographer [16]. These devices and their underlying technologies have been extensively reviewed in the literature (e.g., [15,17-20]). The accuracy of each of these technologies for estimating blood glucose is low $[15,16,19]$ and challenges still lie ahead concerning the portability of the devices, their safety and their cost [15,19].

So far, NI-CGM technologies have generally only been used in very standardized conditions, such as experimental laboratories of hospitals (e.g., [14,21-23]). Yet, to be useful and widely usable, the devices must be precise and accurate in the conditions of daily living [20]. Accordingly, their measurements must be robust to sweating and variations in body temperature. These factors have often been cited as disruptive for non-invasive systems. The proper functioning of the device in everyday life and especially during periods of physical activity is essential because even a low physical activity after a meal affects significantly glucose variability in diabetic patients [24]. Moreover, hypoglycemia can occur during exercise, even moderate, or few hours later [25-27]. Being able to cope with these challenges is an important attribute of NI-CGM technologies, because participation in physical activity is recommended for T1DM without complications [28], resulting in both psychological and clinical benefits with improvements in cardiovascular function [29].

Currently, a number of biosensors, mostly non-invasive ones, have been developed for monitoring patients' physical activity and cardiac data (e.g., electrocardiograms-ECGs). They have proved valuable for detecting the onset and the end of physical activity in T1DM patients. The combination of two sensors devices, an ActiGraph wGT3X-BT activity monitor (ActiGraph, Pensacola, FL, USA) and a heart rate monitor (Polar ${ }^{\circledR}$ Electro Inc., Lake Success, NY, USA) can be used to detect the onset of physical activity within about five minutes by which time glucose levels measured by CGM is only $\pm 1 \mathrm{mg} / \mathrm{dL}$ on average [30]. Similarly, a model applied to data from an accelerometer and heart rate monitor (Zephyr Biopatch, Zephyr Technology, Annapolis, MD, USA) worn by 13 T1DM inpatients have been shown to detect a moderate exercise with a good sensitivity (97.2\%) and specificity $(99.5 \%)$ [31].

Moreover recent studies used physical activity and vital sign sensors to maintain euglycemia and predict hypoglycemia. Some of these devices can directly estimate the blood glucose concentration based on physiological variables. The algorithms used to achieve this have been designed based on research demonstrating changes in cardiac characteristics, such as heart rate and QT interval, during hypoglycemia and hyperglycemia (e.g., [32-39]). Other devices integrate the parameters related to the physical activity and/or cardiac function in the estimation of blood glucose level provided by CGM or NI-CGM.

The aim of this article is review biosensors based on physiological parameters related to physical activity, that were used to improve glucose monitoring in T1DM patients. Section 2 provides beforehand an overview of biosensors used to analyze the influence of physical activity on glucose levels and the information they provide on glucose variations in T1DM individuals. Section 3 considers the estimation of glucose levels based solely on physiological signals, related to exercise, and provided by biosensors. Sections 4 and 5 review the combined use of sensors monitoring physical activity and glucose tracking via CGMs and NI-CGMs, respectively. In each section the underlying designs of these technological advances are highlighted and their benefits and weaknesses discussed. Research studies 
evaluating these sensors on T1DM patients are detailed and assessed with regard to clinical outcomes (blood glucose level control) but, where data is available, also patient satisfaction. Based on the analysis of these emerging technologies we outline, in Section 6, directions for improvements in the design and performance of current and future devices.

\section{Glucose Dynamic during Sensor-Monitored Physical Exercise}

Predicting precise blood glucose concentration during active everyday life and physical exercise requires detailed information on the influence of physical activity on glucose level. To our knowledge, only two studies have addressed the precise relationship between exercise and glucose trends with biosensors, in T1DM patients. They performed a tight temporal tracking of vital signs during physical activity following a meal [24] and during moderate physical activity mimicking daily activities [40]. The technology used in both cases was the Physical Activity Monitoring System (PAMS; Table 1). This sensor combines two tri-axial accelerometers (CXL02LF3-R; Crossbow Technology, San Jose, CA, USA) and four inclinometers (CXTA02; Crossbow Technology) for determining body posture and the individual's movements. Data were collected every half second. The system is quite cumbersome with the two accelerometers placed at the base of the spine and four inclinometers fastened on each side of the body at the trunk and thigh levels, and special underwear required for fitting them. Moreover, because the PAMS only provided data relating to physical activity, three devices were needed: the PAMS, the CGM and the insulin pump, if necessary for the patient.

In their research, Zecchin et al. [40] gathered data on control patients ( $N=20)$ and T1DM patients $(\mathrm{N}=19)$ over four days. For control and diabetic patients, the authors showed that moderate physical activity, corresponding to a daily activity, was associated with changes in glucose level, estimated by the first- and second-order glucose concentration time derivatives. Correlation degrees were stronger for diabetic patients but occurred 5-10 min later. For these individuals the decrease in glycemic concentration following exercise was maximal after $15 \mathrm{~min}$. The increase in glucose level following the beginning of the rest period peaked after about $15 \mathrm{~min}$. From a clinical point of view the slower glucose decline with physical activity should be taken into account by T1DM subjects when adjusting their basal insulin.

Physical activity was also found to significantly reduce postprandial glucose excursions in T1DM and healthy participants [24]. Thus, based on data collected in T1DM patients between 30 min before to $4.5 \mathrm{~h}$ after a meal, the excursions, estimated by the incremental glucose area above basal, was reduced by $59 \%$ (from $18.4 \mathrm{mmol} / \mathrm{L} / 270 \mathrm{~min}$ for meals followed by inactivity to $7.5 \mathrm{mmol} / \mathrm{L} / 270 \mathrm{~min}$ for meals followed by walking). For control participants, the decrease was 53\% (from $9.6 \mathrm{mmol} / \mathrm{L} / 270 \mathrm{~min}$ for meals followed by inactivity to $4.5 \mathrm{mmol} / \mathrm{L} / 270 \mathrm{~min}$ for meals followed by walking). These results provide thorough quantitative evaluations of the effect of physical activity on glucose dynamic. For future research, this information should be added to the algorithm of closed-loop system for a better prediction of insulin infusion and a tighter control of glucose level when exercising.

\section{Sensors Estimating Glucose Level Based on Physical Activity Signals}

The glucose concentration can be directly estimated from physiological parameter values. This has been done using the multisensory device SenseWear ${ }^{\circledR}$ Pro Armband (SWA [41]; Table 1). This multisensory technology was developed by the firm BodyMedia (Pittsburgh, PA, USA). As its name indicates, it is worn around the arm, and two ECG electrodes are placed on the arm and shoulder. The SenseWear ${ }^{\circledR}$ collects physiological data from five types of in-built sensors. A two dimension accelerometer registers the position and movement of the arm and of the body, a heat-flux sensor and a thermistor measure the dissipated heat from the body, as well as the body and surrounding temperature, a galvanic sensor measures the conductivity of the skin, and two ECG electrodes measure the cardiac electrical activity. 
Table 1. Sensors tested in relation with physical activity in T1DM patients and their specific use in research articles.

\begin{tabular}{|c|c|c|c|c|}
\hline General Purpose & Product & Company & Sensors & Specific Use in the Articles \\
\hline $\begin{array}{l}\text { Monitoring glucose dynamic } \\
\text { during physical exercise }\end{array}$ & $\begin{array}{l}\text { Physical Activity Monitoring } \\
\text { System (PAMS) }\end{array}$ & $\begin{array}{l}\text { Crossbow Technology, San } \\
\text { Jose, CA, USA }\end{array}$ & $\begin{array}{c}-2 \text { tri-axial accelerometers (CXL02LF3-R) } \\
-4 \text { inclinometers (CXTA02) }\end{array}$ & $\begin{array}{c}\text { Evaluation of glucose dynamic during physical } \\
\text { exercise }[24,40]\end{array}$ \\
\hline $\begin{array}{l}\text { Physiological signals to estimate } \\
\text { glucose level }\end{array}$ & $\begin{array}{l}\text { BodyMedia SenseWear } \\
\text { Pro Armband }\end{array}$ & $\begin{array}{l}\text { SWA; BodyMedia, Inc, } \\
\text { Pittsburgh, PA, USA }\end{array}$ & $\begin{array}{c}\text {-A 2-axis accelerometer } \\
\text {-Heat-flux sensor } \\
\text {-Thermistors } \\
\text {-Galvanic skin response sensor } \\
\text {-ECG electrodes }\end{array}$ & $\begin{array}{l}\text { Direct estimation of glucose level based on } \\
\text { multisensor data [41] }\end{array}$ \\
\hline \multirow{5}{*}{ Vital signals and CGM } & \multirow{2}{*}{ Zephyr BioHarness $^{\mathrm{TM}} 3$} & \multirow{2}{*}{$\begin{array}{l}\text { Zephyr Technology, } \\
\text { Annapolis, MD, USA }\end{array}$} & \multirow{2}{*}{$\begin{array}{l}\text {-Heart rate } \\
\text {-A 3-axis accelerometer }\end{array}$} & $\begin{array}{c}\text { Integration of heart rate and accelerometer } \\
\text { monitoring in the glucose level estimation } \\
\text { algorithm [42] }\end{array}$ \\
\hline & & & & $\begin{array}{l}\text { Integration of accelerometer monitoring in the } \\
\text { glucose level estimation algorithm [43] }\end{array}$ \\
\hline & $\begin{array}{l}\text { Sport Watch: Polar: } \\
\text { model RS800CX }\end{array}$ & $\begin{array}{l}\text { Polar }^{\circledast} \text {, Lake Success, } \\
\text { NY, USA }\end{array}$ & -Heart rate & $\begin{array}{l}\text { Integration of heart rate monitoring in the glucose } \\
\text { level estimation algorithm [44] }\end{array}$ \\
\hline & $\begin{array}{l}\text { Digital Holter monitor, } \\
\text { SpiderView Plus }\end{array}$ & $\begin{array}{c}\text { ELA Medical, } \\
\text { Montrouge, France }\end{array}$ & -ECG monitor & $\begin{array}{l}\text { Integration of heart rate variability in the glucose } \\
\text { level estimation algorithm }[45,46]\end{array}$ \\
\hline & $\begin{array}{l}\text { BodyMedia SenseWear } \\
\text { Pro3 Armband }\end{array}$ & $\begin{array}{l}\text { SWA; BodyMedia, Inc, } \\
\text { Pittsburgh, PA, USA }\end{array}$ & $\begin{array}{c}\text {-A 2-axis accelerometer } \\
\text {-Heat-flux sensor } \\
\text {-Thermistors } \\
\text {-Galvanic skin response sensor } \\
\text {-ECG electrodes }\end{array}$ & $\begin{array}{l}\text { Integration of energy expenditure and galvanic } \\
\text { skin response in a glucose level estimation } \\
\text { algorithm }[47,48]\end{array}$ \\
\hline \multirow{2}{*}{ Physical activity and NI-CGM } & $\begin{array}{l}\text { Multisensor Glucose } \\
\text { Monitoring System (MGMS) }\end{array}$ & $\begin{array}{l}\text { Solianis Monitoring AG, } \\
\text { Zurich, Switzerland }\end{array}$ & $\begin{array}{c}\text {-Accelerometer } \\
\text {-Temperature sensor } \\
\text {-Humidity sensor } \\
\text {-Optical sensor } \\
\text {-Dielectric spectroscopy (for glucose monitoring) }\end{array}$ & $\begin{array}{l}\text { Integration of temperature, sweat and } \\
\text { acceleration and position in the glucose level } \\
\text { estimation algorithm }[23,49-51]\end{array}$ \\
\hline & SensiumVitals & $\begin{array}{l}\text { Sensium Healthcare Ltd, } \\
\text { London, UK }\end{array}$ & $\begin{array}{c}\text {-Heart rate } \\
\text {-Respiratory rate } \\
\text {-Physical activity } \\
\text {-Blood pH } \\
\text {-Glucose level }\end{array}$ & $\begin{array}{l}\text { Reliability of the cardiac and respiratory rates } \\
\text { estimates [52] }\end{array}$ \\
\hline
\end{tabular}


In this system, the estimation of plasma glucose is based on data collected by the SWA that were downloaded through the CMS prerelease software version 1.0. The data collected from the biosensor were processed using a supervised machine learning based model. It integrates first an algorithm that defines the context (exercise versus no exercise) and then a regression model that provides glucose level estimates for the previously defined context. The quality of the model fit was assessed via a k-fold cross-validation in which all subjects minus one are used to train the model and the remaining subject validates the model. This procedure is repeated so that each subject is in turn used for validation.

The SenseWear ${ }^{\circledR}$ device and model-based inference of plasma glucose levels was tested on patients with type 1 and type 2 diabetes [41]. Minute-by-minute estimates were produced by the armband. The study included 41 patients, of which 18 had T1DM. Patients were aged 18-65 years (mean $42.1 \pm 13.8$ ) and the majority were women. Patients with T1DM were diabetic since $10.0 \pm 7.1$ years. A CGM (iPro, Medtronic, Northridge, CA, USA) was placed on each of the patients. The system was not tested in activities of daily life but only in two experimental conditions. For the first of these, glucose levels were artificially raised while, for the second, patients had to walk for $60 \mathrm{~min}$ on a treadmill at a speed of approximately $4 \mathrm{~km} / \mathrm{h}(2.5 \mathrm{mph})$. For both experiments, the glycemic values of T1DM patients estimated with the SWA were correlated with the reference values obtained directly from the glucose analyzer. The correlations were good for the first experiment $(r=0.70, p<0.05)$ and the second one $(r=0.90, p<0.05)$. These correlations were also similar to those obtained between values from the CGM and the reference values (experiment 1: $r=0.75, p<0.05$; experiment 2: $r=0.95$, $p<0.05)$.

This study suggests that the sensor can provide reasonably good estimates of plasma glucose levels. Yet, both experiments also showed that the device is of limited use when it comes to alerting the patient of hypoglycemia, as hypoglycemic episodes occurred during both experiments. Compared to the reference values, the plasma glucose values estimated by SWA during these episodes in the first experiment were not clinically acceptable. Thus, $0 \%$ of the values were in area $\mathrm{A}+\mathrm{B}$ according to Clarke error grid, although the SWA was switched on. In the experiment with the treadmill, $26 \%$ of the values were clinically acceptable (area $A+B)$. These values should be compared to those obtained with CGM. Of the blood glucose levels measured by CGM during the hypoglycemic episodes occurring in experiments 1 and 2, respectively, 36\% and $0 \%$ of the values fell into area $\mathrm{A}$, and none in area $\mathrm{B}$. Accordingly, the SWA and CGM did not provide accurate hypoglycemia predictions compared to the glucose meter.

In the experiments just described, glucose value estimates were obtained under standardized test conditions. The effectiveness of the SWA in T1D patients has yet to be assessed under conditions of everyday life and under uncontrolled physical activity. A SWA (SenseWear Pro3 Body Monitoring System) was tested under free-living conditions on one type 2 diabetic patient [53]. The authors used a mathematical model (Wiener model) to integrate the data provided by the sensor with other variables, such as those related to diet (e.g., carbohydrate and protein intake). The vast majority of estimates provided by the model were clinically acceptable with $90 \%$ of predicted glucose concentrations in area $\mathrm{A}$ and $7 \%$ in area $\mathrm{B}$ according to the Clarke error grid analysis. The percentages concerned all glycemic values (i.e., euglycemia, hypo- and hyperglycemia) and not only hypoglycemia like the previous study [41]. In their article, Rollins et al. [53] also noted poorer model-based predictions of glucose levels in case of high hypoglycemia. The study, although involving only a single patient, showed an interesting approach to the estimation of blood glucose in the conditions of daily life.

One of the parameters included in this study [53] is energy expenditure. Yet, care should be taken with the energy expenditure (EE) estimation provided by the SenseWear Pro3. The EE estimation has been evaluated in older T1DM and T2DM individuals during sessions of walking on a treadmill at various speeds and inclines [54]. The EE values were shown to be weakly underestimated (by $8 \% \pm 17 \%$ ) when the subjects walked uphill $(5 \mathrm{~km} / \mathrm{h}$ and $5 \%$ incline) and strongly overestimated (by $81 \% \pm 24 \%$ ) in case of level walking ( $3 \mathrm{~km} / \mathrm{h}$ with $0 \%$ incline) [55]. The large overestimation at low 
efforts, in particular, might cause problems when using activity data to infer blood glucose levels for diabetic patients with a poor physical condition.

Despite these drawbacks, the use of mobile sensors to assess blood glucose level directly through physical activity related parameters is very promising and should be further developed. Finally the only information given in these articles about patient satisfaction indicates that no pain associated with the use of the SWA was reported by the patients [41].

\section{Integration of Sensors-Based Physiological Parameters with CGM Data}

Estimates of plasma glucose with CGM are not always reliable and it has been shown that physical exercise disrupts blood glucose dynamics, and can render the maintenance of euglycemia more challenging $[24,40]$. As a consequence, some authors have developed an approach to integrate vital signals during exercise to increase the prediction accuracy of glucose levels, based on CGM data. Thus, the information on, for instance, the patient's physical activity or heart rate, is used not only to directly estimate glucose levels, as presented previously, but, in this case, to improve the accuracy of the algorithms involved in the development of artificial pancreas.

In this context, Stenerson et al. [42] used the Zephyr BioHarness ${ }^{\mathrm{TM}} 3$ of the Zephyr Technology Company (Annapolis, MD, USA; Table 1). It is worn as a belt at the chest level and combines two sensors. The acceleration data, estimated by a 3-axis accelerometer, and heart rate data are recorded every second. The patients need to wear a harness, but also a CGM and an insulin pump. In a first study, the authors [42] collected, in 22 T1DM patients, the physiological and life-style data issued from these three systems. Data were collected throughout the patients' daily activities, on average during 4.9 days (from 1 to 16 days). Glucose levels estimated by the CGM were obtained every five minutes. The authors developed an improved algorithm predicting glucose levels and stopping the insulin pump when the level is below the threshold of $70 \mathrm{mg} / \mathrm{dL}$. With simulations, the authors pointed out that if the original algorithm reduces the number of hypoglycemia incidents by $62 \%$, adding information on heart rate (HR) allows to reduce their frequency by $71 \%$ and data on acceleration by $74 \%$. The combination of data of HR and acceleration reduces hypoglycemia by $76 \%$. These results show the benefit of accelerometer data but do not justify the use of a heart rate sensor. However, data on the number of false positives hypoglycemia (i.e., hypoglycemia detected by simulation but not real) were not mentioned.

The research by simulation was completed by a study of 18 T1DM patients gathered for a football game [43]. This study was designed to test the effectiveness of the improved algorithm with the acceleration data. The results however indicated that the algorithm has failed to prevent hypoglycemia in patients using it compared to patients using their usual basal insulin rate. Patients on algorithmic glycemic control did not show higher rates of hyperglycemia. This is an advantage since the current practice is to turn off the insulin pump before exercise, which often leads to hyperglycemia. In terms of telemedicine, in this study on Zephyr, the data from the accelerometer can be read in real time through the SenseView application (Mobili d.o.o., Ljubljana, Slovenia) on a mobile phone. It remains however that this system is only at an experimental stage since the insulin pump of patients using the algorithm was activated and deactivated manually by the staff in charge of the study. Finally, no adverse effect has been shown due to the wearing the Zephyr system.

If Stenerson et al. $[42,43]$ retained the acceleration as the most important signal to integrate in the algorithm, in other studies, information on HR was included in order to modulate the amount of injected insulin $[44,56,57]$. Heart rate data were collected using a RS800CX sports watch from the Polar ${ }^{\circledR}$ firm (Lake Success, NY, USA; Table 1). These data were integrated into an algorithm implemented on a DiAs artificial pancreas platform. DiAs was also connected to an insulin pump and to a CGM. It runs on an Android ${ }^{\circledR}$ phone (Google, Mountain View, CA, USA) and is controlled by the patient that may introduce information such as the carbohydrate intake.

To evaluate this approach, the authors performed a study on 12 T1DM patients with a randomized crossover design [44]. They compared the effectiveness of the classical algorithm with the one enriched 
with heart rate values to prevent hypoglycemia during exercise. They showed a significant decrease of the reduction of blood glucose during exercise, and reduced hypoglycemia during moderate exercise, although this last difference was not significant. The advantages of this system, during the recovery phase and during the night, are less clear. Finally in case of physical activity, the system DiAs is manually informed by pressing a button when the HR exceeds $125 \%$ of the patient's HR at rest. It should be further optimized to become automatic and also controlled to limit false alerts.

Other authors focused also on the heart rate signals, but using different devices. Thus, heart rate variability (HRV) was collected through lead II with a digital Holter monitor (SpiderView Plus, ELA Medical, Montrouge, France; Table 1) and combined with glucose values measured with CGM to predict and to improve the detection of hypoglycemia $[45,46]$. The combination initially tested in a clinical research setting [45] was evaluated in free-living conditions on 21 adult patients [46]. The algorithm combining glucose values with those of HRV shows a good response for both the sensitivity and specificity of hypoglycemia detection with, respectively, values of $91 \%$ and $100 \%$ for 20 min prediction interval.

The SenseWear, employed by Sobel et al. [41] to directly estimate glucose concentration (see Section 3), has also been used for combining physiological variables with blood glucose measurements obtained by CGM [47,48]. This combination is expected to provide better estimates of the insulin amount to inject. In these studies the major physiological parameters taken into account to indicate physical activity are the energy expenditure and the galvanic skin response. With the addition of these physiological data, glucose levels are better controlled. This adjustment is carried out directly, i.e., without a user intervention to announce, to the system, the patient's physical activity or food intake [47]. The device has been enriched by an alarm indicating efficiently the risk of hypoglycemia before their occurrence [48].

As mentioned, these studies did not directly estimate glucose levels from the sensor-based physiological values but rather combine these data with CGM measurements to provide an increased precision in glucose concentration predictions. This approach offers an interesting reflection on ways to combine, with mathematical algorithms, plasma glucose data with physical activity levels. They also allow an assessment of various sensors (Zephyr Bioharness, Sports Watch ... ) that could be used in other settings.

\section{Integration of Sensors-Based Physiological Parameters with NI-CGM}

In the last section we pointed out that physiological data can be combined with glucose level values measured by CGM. Similarly research has been conducted to improve the accuracy of NI-CGMs through the integration of several physiological factors $[23,49,50]$. These studies were conducted with the Multisensor Glucose Monitoring System (MGMS) developed by Solianis Monitoring AG (Zurich, Switzerland; Table 1). The device includes dielectric spectroscopy and optical sensors. Glucose level variations engenders changes in the properties of tissues, notably in cell membrane conductivity, that are tracked by the dielectric spectroscopy electrodes. An important feature is that the sensors for estimating glucose concentration as well as those monitoring potential disturbing physiological factors are integrated in the same device. Thereby, the apparatus, worn on the upper arm, also tracks the subject's temperature, sweating and movement, among others. The monitoring of glucose levels changes through this system was subsequently improved through the implementation of more sophisticated mathematical models combining the various variables monitored by the device [49,50].

The results obtained are globally good, with $92 \%$ of the results in the $A+B$ region of the Clarke error grid analysis [50]. Nevertheless, it would have been interesting to know if the behavior of the system is specifically reliable under hypoglycemia and hyperglycemia since these deviations in glucose levels were provoked in the patients.

One study has used Monte Carlo simulations to test the robustness of the system to a disruptive factor, sweating [51]. The authors showed that the system does not need to be re-calibrated after sweating event, which is appealing for use in everyday life. 
The SensiumVitals (Sensium Healthcare Ltd, London, UK) is another device that combines multiple sensors into a small and lightweight single-use system. The device can measure various physiological parameters, including heart and respiratory rates, physical activity, blood pH or glucose level $[58,59]$. Blood glucose is monitored through an ion sensitive field effect transistor. The principle is based on variations in ion concentration resulting from glucose level changes [60]. The values of the physiological variables can be transmitted wirelessly. The reliability of this system for the estimation of cardiac and respiratory rates were evaluated with diabetic inpatients [48]. The SensiumVitals accuracy assessment does not appear to have been conducted for glucose level estimation on inpatients or outpatients. The integration of different physiological parameters in the determination of glucose level has not been approached either.

\section{Conclusions}

The reviewed studies indicate the appeal of devices using physiological signals related to physical activity and their potential to improve the management of diabetes in a near future. Thus physical activity, although beneficial for diabetic patients, constitutes an element that disrupts glucose dynamics and generates blood glucose regulation problems during and after exercise. These sensors provided valuable results to estimate glucose concentration either based solely on physical activity parameters or in conjunction with CGM or NI-CGM systems. In these last cases, vital signs are used to modulate the glucose estimations provided by the CGM and NI-CGM devices.

These systems tracking physiological signals were assessed for their validity and accuracy to infer blood levels and to detect hypoglycemia. In this respect, their performance was often compared with CGM-based glucose estimations. Nevertheless, evaluations of their therapeutic superiority compared to gold standard treatment globally still need to be conducted. This would for instance allow one to determine if the new devices reduce the risk of hypoglycemia or if the glycaemia is adequately controlled in the long-term. The use of the largely recognized glycated hemoglobin (HbA1c) would allow to appreciate their efficiency to control blood glucose for three months [61].

In terms of communication, a key point concerns the need to develop compatible systems with the computerized patient records of clinical institutions $[62,63]$. This will promote the sharing of patient data between healthcare providers (doctors, nurses...) and should improve patient care [64,65]. The interoperability of multisensory devices for diabetic patients has been investigated to allow their connection with health monitoring platforms [66,67]. The proposed architecture follow the standards of Health Level 7 (HL7). Interoperability between systems is essential to ensure changes in the functioning of care. Healthcare provision initially mostly occurring in hospital settings and private practice, moves to a patient-centered process, much more open as occurring at all times and in all places $[68,69]$. Data could also be combined with other sources of information such as "social media" to generate clinical and well-being recommendations [70].

Wireless data transmission, to health professionals, to the patient and to his relatives, is not yet possible with all devices. Information and communication technology (ICT) will nevertheless undoubtedly bring an additional advantage to biosensors and their users. ICT offers to diabetic individuals a diversity of solutions to help them better manage the disease. ICT can for instance encompass internet, mobile phone applications (mHealth: [71-73]), and telemedicine technologies based on decision support. These technologies were, and still are, the subject of much literature reviews showing a general, although mild, advantage of these technologies for diabetic patients [74-77]. Notably they facilitate patient self-management [63], a better control of nutrition [76] and a metabolic control pointed out by a low reduction in glycated hemoglobin [78]. The patients also appear satisfied with these systems and present enhanced well-being and feeling of disease control [79].

Patient satisfaction has not been investigated for the presented devices tracking physical activity parameters. Only sparse general information on patients was mentioned in the articles, such as the absence of pain or discomfort. Studying patient satisfaction in regard with new technologies is in fact not a generality. A literature review indicates that this outcome is envisaged in less than $50 \%$ of the 
studies testing ICT [63]. Yet it is well known that patient satisfaction constitutes a significant part for a successful implementation. However, in recent years, primary studies published on patient satisfaction with technological advances have increased (e.g., [80,81]), as well as systematic reviews (e.g., [82]).

Acknowledgments: This work was financed by the Swiss Nano-Tera Research program (D1NAMO project). The authors would like to thank M. Reuter for English correction.

Conflicts of Interest: The authors declare no conflict of interest.

\section{Abbreviations}

The following abbreviations are used in this manuscript:

$\begin{array}{ll}\text { CGM } & \text { Continuous Glucose Monitoring } \\ \text { ECG } & \text { Electrocardiogram } \\ \text { HbA1c } & \text { Glycated hemoglobin } \\ \text { HL7 } & \text { Health Level 7 } \\ \text { HR } & \text { Heart Rate } \\ \text { HRV } & \text { Heart Rate Variability } \\ \text { ICT } & \text { Information and Communication Technology } \\ \text { MGMS } & \text { Multisensor Glucose Monitoring System } \\ \text { NI-CGM } & \text { Non-Invasive Continuous Glucose Monitoring } \\ \text { PAMS } & \text { Physical Activity Monitoring System } \\ \text { SWA } & \text { SenseWear }{ }^{\circledR} \text { Pro Armband } \\ \text { T1DM } & \text { Type 1 diabetes mellitus }\end{array}$

\section{References}

1. Afsar, B. Disruption of circadian blood pressure, heart rate and the impact on glycemic control in type 1 diabetes. Diabetes Metab. Syndr. 2015, 9, 359-363. [CrossRef] [PubMed]

2. Frier, B.M. Hypoglycaemia in diabetes mellitus: Epidemiology and clinical implications. Nat. Rev. Endocrinol. 2014, 10, 711-722. [CrossRef] [PubMed]

3. Burge, M.R.; Mitchell, S.; Sawyer, A.; Schade, D.S. Continuous glucose monitoring: the future of diabetes management. Diabetes Spectr. 2008, 21, 112-119. [CrossRef]

4. Wagner, J.; Malchoff, C.; Abbott, G. Invasiveness as a barrier to self-monitoring of blood glucose in diabetes. Diabetes Technol. Ther. 2005, 7, 612-619. [CrossRef] [PubMed]

5. Ghafar-Zadeh, E. Wireless integrated biosensors for point-of-care diagnostic applications. Sensors 2015, 15, 3236-3261. [CrossRef] [PubMed]

6. Pickup, J.C.; Freeman, S.C.; Sutton, A.J. Glycaemic control in type 1 diabetes during real time continuous glucose monitoring compared with self-monitoring of blood glucose: meta-analysis of randomised controlled trials using individual patient data. BMJ 2011, 343, 1-14. [CrossRef] [PubMed]

7. Choudhary, P.; Ramasamy, S.; Green, L.; Gallen, G.; Pender, S.; Brackenridge, A.; Amiel, S.A.; Pickup, J.C. Real-time continuous glucose monitoring significantly reduces severe hypoglycemia in hypoglycemia-unaware patients with type 1 diabetes. Diabetes Care. 2013, 36, 4160-4162. [CrossRef] [PubMed]

8. Mauras, N.; Fox, L.; Englert, K.; Beck, R.W. Continuous glucose monitoring in type 1 diabetes. Endocrine 2013, 43, 41-50. [CrossRef] [PubMed]

9. Langendam, M.; Luijf, Y.M.; Hooft, L.; Devries, J.H.; Mudde, A.H.; Scholten, R.J. Continuous glucose monitoring systems for type 1 diabetes mellitus. Cochrane Database Syst. Rev. 2012, 1. [CrossRef]

10. Damiano, E.R.; McKeon, K.; El-Khatib, F.H.; Zheng, H.; Nathan, D.M.; Russell, S.J. A comparative effectiveness analysis of three continuous glucose monitors: the navigator, G4 platinum, and Enlite. J. Diabetes Sci. Technol. 2014, 8, 699-708. [CrossRef] [PubMed]

11. Peyser, T.; Dassau, E.; Breton, M.; Skyler, J.S. The artificial pancreas: current status and future prospects in the management of diabetes. Ann. N. Y. Acad. Sci. 2014, 1311, 102-123. [CrossRef] [PubMed] 
12. Kovatchev, B.; Anderson, S.; Heinemann, L.; Clarke, W. Comparison of the numerical and clinical accuracy of four continuous glucose monitors. Diabetes Care. 2008, 31, 1160-1164. [CrossRef] [PubMed]

13. Aloraefy, M.; Pfefer, T.J.; Ramella-Roman, J.C.; Sapsford, K.E. In vitro evaluation of fluorescence glucose biosensor response. Sensors 2014, 14, 12127-12148. [CrossRef] [PubMed]

14. Larin, K.V.; Eledrisi, M.S.; Motamedi, M.; Esenaliev, R.O. Noninvasive blood glucose monitoring with optical coherence tomography: A pilot study in human subjects. Diabetes Care. 2002, 25, 2263-2267. [CrossRef] [PubMed]

15. Tura, A.; Maran, A.; Pacini, G. Non-invasive glucose monitoring: Assessment of technologies and devices according to quantitative criteria. Diabetes Res. Clin. Pract. 2007, 77, 16-40. [CrossRef] [PubMed]

16. Nunnold, T.; Colberg, S.R.; Herriott, M.T.; Somma, C.T. Use of the noninvasive Glucowatch Biographer during exercise of varying intensity. Diabetes Technol. Ther. 2004, 6, 454-462. [CrossRef] [PubMed]

17. Yilmaz, T.; Foster, R.; Hao, Y. Detecting vital signs with wearable wireless sensors. Sensors 2010, 10, 10837-10862. [CrossRef] [PubMed]

18. Ciudin, A.; Hernández, C.; Simó, R. Non-invasive methods of glucose measurement: Current status and future perspectives. Curr. Diabetes Rev. 2012, 8, 48-54. [CrossRef] [PubMed]

19. So, C.-F.; Choi, K.-S.; Wong, T.K.S.; Chung, J.W.Y. Recent advances in noninvasive glucose monitoring. Med. Devices 2012, 5, 45-52.

20. Chowdhury, K.; Srivastava, A.; Sharma, N.; Sharma, S. Prospective Analysis of Developing Noninvasive Blood Glucose Monitoring Biosensors for Diabetic Population. Biosci. Biotechnol. Res. Asia. 2014, 11, 1639-1647. [CrossRef]

21. Harman-Boehm, I.; Gal, A.; Raykhman, A.M.; Zahn, J.D.; Naidis, E.; Mayzel, Y. Noninvasive glucose monitoring: a novel approach. J. Diabetes Sci. Technol. 2009, 3, 253-260. [CrossRef] [PubMed]

22. Harman-Boehm, I.; Gal, A.; Raykhman, A.M.; Naidis, E.; Mayzel, Y. Noninvasive glucose monitoring: Increasing accuracy by combination of multi-technology and multi-sensors. J. Diabetes Sci. Technol. 2010, 4, 583-595. [CrossRef] [PubMed]

23. Caduff, A.; Mueller, M.; Megej, A.; Dewarrat, F.; Suri, R.E.; Klisic, J.; Donath, M.; Zakharov, P.; Schaub, D.; Stahel, W.A.; et al. Characteristics of a multisensory system for non-invasive glucose monitoring with external validation and prospective evaluation. Biosens. Bioelectron. 2011, 26, 3794-3800. [CrossRef] [PubMed]

24. Manohar, C.; Levine, J.A.; Nandy, D.K.; Saad, A.; Dalla Man, C.; McCrady-Spitzer, S.K.; Basu, R.; Cobelli, C.; Carter, R.E.; Basu, A.; Kudva, Y.C. The effect of walking on postprandial glycemic excursion in patients with type 1 diabetes and healthy people. Diabetes Care. 2012, 35, 2493-2499. [CrossRef] [PubMed]

25. MacDonald, M.J. Postexercise late-onset hypoglycemia in insulin dependent diabetic patients. Diabetes Care. 1987, 10, 584-588. [CrossRef] [PubMed]

26. Diabetes Research in Children Network (DirecNet) Study Group. Prevention of hypoglycemia during exercise in children with type 1 diabetes by suspending basal insulin. Diabetes Care. 2006, 29, 2200-2204.

27. Guelfi, K.J.; Ratnam, N.; Smythe, G.A.; Jones, T.W.; Fournier, P.A. Effect of intermittent high-intensity compared with continuous moderate exercise on glucose production and utilization in individuals with type 1 diabetes. Am. J. Physiol. Endocrinol. MeTable 2007, 292, E865-E870. [CrossRef] [PubMed]

28. American Diabetes Association. Physical activity/exercise and diabetes. Diabetes Care 2004, 27, S58-S62.

29. Valletta, J.J.; Chipperfield, A.J.; Clough, G.F.; Byrne, C.D. Daily energy expenditure, cardiorespiratory fitness and glycaemic control in people with type 1 diabetes. PLoS ONE 2014, 9, e97534. [CrossRef] [PubMed]

30. Dasanayake, I.S.; Bevier, W.C.; Castorino, K.; Pinsker, J.E.; Seborg, D.E.; Doyle, F.J.; Dassau, E. Early detection of physical activity for people with type 1 diabetes mellitus. J. Diabetes Sci. Technol. 2015, 9, 1236-1245. [CrossRef] [PubMed]

31. Jacobs, P.G.; Resalat, N.; El Youssef, J.; Reddy, R.; Branigan, D.; Preiser, N.; Condon, J.; Castle, J. Incorporating an exercise detection, grading, and hormone dosing algorithm into the artificial pancreas using accelerometry and heart rate. J. Diabetes Sci. Technol. 2015, 9, 1175-1184. [CrossRef] [PubMed]

32. Lipponen, J.A.; Kemppainen, J.; Karjalainen, P.A.; Laitinen, T.; Mikola, H.; Käri, T.; Tarvainen, M.P. Dynamic estimation of cardiac repolarization characteristics during hypoglycemia in healthy and diabetic subjects. Physiol. Meas. 2011, 32, 649-660. [CrossRef] [PubMed] 
33. Lipponen, J.A.; Kemppainen, J.; Karjalainen, P.A.; Laitinen, T.; Mikola, H.; Käri, T.; Tarvainen, M.P. Hypoglycemia detection based on cardiac repolarization features. In Proceedings of the 2011 Annual International Conference of the IEEE Engineering in Medicine and Biology Society, Boston, MA, USA, 30 August-3 September 2011; pp. 4697-4700.

34. Nguyen, L.L.; Su, S.; Nguyen, H.T. Identification of hypoglycemia and hyperglycemia in Type 1 diabetic patients using ECG parameters. In Proceedings of the 2012 Annual International Conference of the IEEE Engineering in Medicine and Biology Society, San Diego, CA, USA, 28 Auguest-1 September 2012; pp. 2716-2719.

35. Nguyen, L.L.; Su, S.; Nguyen, H.T. Effects of hyperglycemia on variability of RR, QT and corrected QT intervals in Type 1 diabetic patients. In Proceedings of the 2013 35th Annual International Conference of the IEEE Engineering in Medicine and Biology Society (EMBC), Osaka, Japan, 3-7 July 2013; pp. 1819-1822.

36. Christensen, T.F.; Lewinsky, I.; Kristensen, L.E.; Randløv, J.; Poulsen, J.U.; Eldrup, E.; Pater, C.; Hejlesen, O.K.; Struijk, J.J. QT interval prolongation during spontaneous episodes of hypoglycaemia in type 1 diabetes: The impact of heart rate correction. Diabetologia 2010, 53, 2036-2041. [CrossRef] [PubMed]

37. Christensen, T.F.; Cichosz, S.L.; Tarnow, L.; Randløv, J.; Kristensen, L.E.; Struijk, J.J.; Eldrup, E.; Hejlesen, O.K. Hypoglycaemia and QT interval prolongation in type 1 diabetes-bridging the gap between clamp studies and spontaneous episodes. J. Diabetes Complicat. 2014, 28, 723-728. [CrossRef] [PubMed]

38. Nuryani, N.; Ling, S.S.H.; Nguyen, H.T. Electrocardiographic signals and swarm-based support vector machine for hypoglycemia detection. Ann. Biomed. Eng. 2012, 40, 934-945. [CrossRef] [PubMed]

39. Nguyen, L.L.; Su, S.; Nguyen, H.T. Neural network approach for non-invasive detection of hyperglycemia using electrocardiographic signals. In Proceedings of the 2014 36th Annual International Conference of the IEEE Engineering in Medicine and Biology Society, Chicago, IL, USA, 26-30 August 2014; pp. 4475-4478.

40. Zecchin, C.; Facchinetti, A.; Sparacino, G.; Dalla Man, C.; Manohar, C.; Levine, J.A.; Basu, A.; Kudva, Y.C.; Cobelli, C. Physical activity measured by physical activity monitoring system correlates with glucose trends reconstructed from continuous glucose monitoring. Diabetes Technol. Ther. 2013, 15, 836-44. [CrossRef] [PubMed]

41. Sobel, S.I.; Chomentowski, P.J.; Vyas, N.; Andre, D.; Toledo, F.G. Accuracy of a novel noninvasive multisensor technology to estimate glucose in diabetic subjects during dynamic conditions. J. Diabetes Sci. Technol. 2014, 8, 54-63. [CrossRef] [PubMed]

42. Stenerson, M.; Cameron, F.; Wilson, D.M.; Harris, B.; Payne, S.; Bequette, W.; Buckingham, B.A. The impact of accelerometer and heart rate data on hypoglycemia mitigation in type 1 diabetes. J. Diabetes Sci. Technol. 2014, 8, 64-69. [CrossRef] [PubMed]

43. Stenerson, M.; Cameron, F.; Payne, S.R.; Payne, S.L.; Ly, T.T.; Wilson, D.M.; Buckingham, B.A. The impact of accelerometer use in exercise-associated hypoglycemia prevention in type 1 diabetes. J. Diabetes Sci. Technol. 2015, 9, 80-85. [CrossRef] [PubMed]

44. Breton, M.D.; Brown, S.A.; Karvetski, C.H.; Kollar, L.; Topchyan, K.A.; Anderson, S.M.; Kovatchev, B.P. Adding heart rate signal to a control-to-range artificial pancreas system improves the protection against hypoglycemia during exercise in type 1 diabetes. Diabetes Technol. Ther. 2014, 16, 506-511. [CrossRef] [PubMed]

45. Cichosz, S.L.; Frystyk, J.; Hejlesen, O.K.; Tarnow, L.; Fleischer, J. A novel algorithm for prediction and detection of hypoglycemia based on continuous glucose monitoring and heart rate variability in patients with type 1 diabetes. J. Diabetes Sci. Technol. 2014, 8, 731-737. [CrossRef] [PubMed]

46. Cichosz, S.L.; Frystyk, J.; Tarnow, L.; Fleischer, J. Combining information of autonomic modulation and CGM measurements enables prediction and improves detection of spontaneous hypoglycemic events. J. Diabetes Sci. Technol. 2015, 9, 132-137. [CrossRef] [PubMed]

47. Turksoy, K.; Quinn, L.T.; Littlejohn, E.; Cinar, A. Multivariable adaptive closed-loop control of an artificial pancreas without meal and activity announcement. Diabetes Technol. Ther. 2013, 15, 386-400. [CrossRef] [PubMed]

48. Turksoy, K.; Quinn, L.T.; Littlejohn, E.; Cinar, A. An integrated multivariable artificial pancreas control system. J. Diabetes Sci. Technol. 2014, 8, 498-507. [CrossRef] [PubMed]

49. Zanon, M.; Sparacino, G.; Facchinetti, A.; Riz, M.; Talary, M.S.; Suri, R.E.; Caduff, A.; Cobelli, C. Non-invasive continuous glucose monitoring: improved accuracy of point and trend estimates of the multisensor system. Med. Biol. Eng. Comput. 2012, 50, 1047-1057. [CrossRef] [PubMed] 
50. Zanon, M.; Sparacino, G.; Facchinetti, A.; Talary, M.S.; Caduff, A.; Cobelli, C. Regularised model identification improves accuracy of multisensor systems for noninvasive continuous glucose monitoring in diabetes management. J. Appl. Math. 2013, 2013, 1-10. [CrossRef]

51. Zanon, M.; Sparacino, G.; Facchinetti, A.; Talary, M.S.; Mueller, M.; Caduff, A.; Cobelli, C. Non-invasive continuous glucose monitoring with multi-sensor systems: A Monte Carlo-based methodology for assessing calibration robustness. Sensors 2013, 13, 7279-7295. [CrossRef] [PubMed]

52. Hernandez-Silveira, M.; Ahmed, K.; Ang, S.-S.; Zandari, F.; Mehta, T.; Weir, R.; Burdett, A.; Toumazou, C.; Brett, S.J. Assessment of the feasibility of an ultralow power, wireless digital patch for the continuous ambulatory monitoring of vital signs. BMJ Open 2015, 5. [CrossRef] [PubMed]

53. Rollins, D.K.; Bhandari, N.; Kleinedler, J.; Kotz, K.; Strohbehn, A.; Boland, L.; Murphy, M.; Andre, D.; Vyas, N.; Welk, G.; et al. Free-living inferential modeling of blood-glucose level using only noninvasive inputs. J. Process. Control. 2010, 20, 95-107. [CrossRef]

54. Vernillo, G.; Savoldelli, A.; Pellegrini, B.; Schena, F. Validity of the SenseWear armband to assess energy expenditure in graded walking. JPAH 2015, 12, 178-183. [CrossRef] [PubMed]

55. Machač, S.; Procházka, M.; Radvanský, J.; Slabý, K. Validation of physical activity monitors in individuals with diabetes: energy expenditure estimation by the Multisensor SenseWear Armband Pro3 and the Step Counter Omron HJ-720 against indirect calorimetry during walking. Diabetes Technol. Ther. 2013, 15, 413-418. [CrossRef] [PubMed]

56. Breton, M.D. Physical activity-The major unaccounted impediment to closed loop control. J. Diabetes Sci. Technol. 2008, 2, 169-174. [CrossRef] [PubMed]

57. Dalla Man, C.; Breton, M.D.; Cobelli, C. Physical activity into the meal glucose-insulin model of type 1 diabetes: In silico studies. J. Diabetes Sci. Technol. 2009, 3, 56-67. [CrossRef]

58. Georgiou, P.; Toumazou, C. Chemical bionics-A novel design approach using ion sensitive field effect transistors. In Proceedings of the 2008 IEEE Biomedical Circuits and Systems Conference, Baltimore, MD, USA, 20-22 November 2008; pp. 229-232.

59. Wong, A.W.; McDonagh, D.; Omeni, O.; Nunn, C.; Hernandez-Silveira, M.; Burdett, A.J. Sensium: An ultra-low-power wireless body sensor network platform: Design \& application challenges. In Proceedings of the 2009 Annual International Conference of the IEEE Engineering in Medicine and Biology Society, Minneapolis, MN, USA, 3-6 September 2009; pp. 6576-6579.

60. Lee, C.-S.; Kim, S.K.; Kim, M. Ion-sensitive field-effect transistor for biological sensing. Sensors 2009, 9, 7111-7131. [CrossRef] [PubMed]

61. Puricel, S.G.; Ruiz, J. Le diabète et l'ère de la télémédecine. Rev. Med. Suisse. 2014, 10, 1246-1248. [PubMed]

62. Chan, M.; Estève, D.; Fourniols, J.-Y.; Escriba, C.; Campo, E. Smart wearable systems: Current status and future challenges. Artif. Intell. Med. 2012, 56, 137-156. [CrossRef] [PubMed]

63. El-Gayar, O.; Timsina, P.; Nawar, N.; Eid, W. A systematic review of IT for diabetes self-management: Are we there yet? Int. J. Med. Inform. 2013, 82, 637-652. [CrossRef] [PubMed]

64. Müller, H.; Schumacher, M.; Godel, D.; Abu Khaled, O.; Mooser, F.; Ding, S. MediCoordination: A practical approach to interoperability in the Swiss health system. Stud. Health Technol. Inform. 2009, 150, $210-214$. [PubMed]

65. Brugés, A.; Bromuri, S.; Barry, M.; Jiménez del Toro, O.; Mazurkiewicz, M.R.; Kardas, P.; Pegueroles, J.; Schumacher, M. Processing diabetes mellitus composite events in MAGPIE. J. Med. Syst. 2016, 40. [CrossRef]

66. Kafali, O.; Bromuri, S.; Sindlar, M.; van der Weide, T.; Aguilar Pelaez, E.; Schaechtle, U.; Alves, B.; Zufferey, D.; Rodriguez-Villegas, E.; Ignaz Schumacher, M.; et al. COMMODITY12: A smart e-health environment for diabetes management. JAISE 2013, 5, 479-502.

67. Zufferey, D.; Bromuri, S.; Schumacher, M. Analyse continue, multicouches et multiparamétriques des diabètes de type 1 et 2. Swiss Med. Inf. 2014, 30. [CrossRef]

68. Teng, X.F.; Zhang, Y.T.; Poon, C.C.Y.; Bonato, P. Wearable Medical Systems for p-Health. IEEE Rev. Biomed. Eng. 2008, 1, 62-74. [CrossRef] [PubMed]

69. Brugés, A.; Bromuri, S.; Pegueroles, J.; Schumacher, M. Current trends in interoperability, scalability, and security of pervasive healthcare systems. In Recent Advances in Ambient Intelligence and Context-Aware Computing; IGI Global: Hershey, PA, USA, 2015; pp. 227-247. 
70. Ali, R.; Siddiqi, M.H.; Idris, M.; Ali, T.; Hussain, S.; Huh, E.-N.; Kang, B.H.; Lee, S. GUDM: Automatic generation of unified datasets for learning and reasoning in healthcare. Sensors 2015, 15, 15772-15798. [CrossRef] [PubMed]

71. Årsand, E.; Frøisland, H.; Skrøvseth, S.O.; Chomutare, T.; Tatara, N.; Hartvigsen, G.; Tufano, J.T. Mobile health applications to assist patients with diabetes: Lessons learned and design implications. J. Diabetes Sci. Technol. 2012, 6, 1197-1206. [CrossRef] [PubMed]

72. Mulvaney, S.A.; Ritterband, L.M.; Bosslet, L. Mobile intervention design in diabetes: Review and recommendations. Curr. Diab. Rep. 2011, 11, 486-493. [CrossRef] [PubMed]

73. Caburnay, C.A.; Graff, K.; Harris, J.K.; McQueen, A.; Smith, M.; Fairchild, M.; Kreuter, M.W. Evaluating diabetes mobile applications for health literate designs and functionality. Prev. Chronic Dis. 2015, 12, 1-13. [CrossRef] [PubMed]

74. Farmer, A.; Gibson, O.J.; Tarassenko, L.; Neil, A. A systematic review of telemedicine interventions to support blood glucose self-monitoring in diabetes. Diabet. Med. 2005, 22, 1372-1378. [CrossRef] [PubMed]

75. Russell-Minda, E.; Jutai, J.; Speechley, M.; Bradley, K.; Chudyk, A.; Petrella, R. Health Technologies for Monitoring and Managing Diabetes: A Systematic Review. J. Diabetes Sci. Technol. 2009, 3, 1460-1471. [CrossRef] [PubMed]

76. Baron, J.; McBain, H.; Newman, S. The impact of mobile monitoring technologies on glycosylated hemoglobin in diabetes: A systematic review. J. Diabetes Sci. Technol. 2012, 6, 1185-1196. [CrossRef] [PubMed]

77. Sheehy, S.; Cohen, G.; Owen, K.R. Self-management of diabetes in children and young adults using technology and smartphone applications. Curr. Diabetes Rev. 2014, 10, 298-301. [CrossRef] [PubMed]

78. Marcolino, M.S.; Maia, J.X.; Alkmim, M.B.M.; Boersma, E.; Ribeiro, A.L. Telemedicine application in the care of diabetes patients: Systematic review and meta-analysis. PLoS ONE 2013, 8. [CrossRef] [PubMed]

79. Boaz, M.; Hellman, K.; Wainstein, J. An automated telemedicine system improves patient-reported wellbeing. Diabetes Technol. Ther. 2009, 11, 181-186. [CrossRef] [PubMed]

80. Lawton, J.; Kirkham, J.; Rankin, D.; Barnard, K.; Cooper, C.L.; Taylor, C.; Heller, S.; Elliott, J.; REPOSE Group. Collaborators. Perceptions and experiences of using automated bolus advisors amongst people with type 1 diabetes: A longitudinal qualitative investigation. Diabetes Res. Clin. Pract. 2014, 106, 443-450. [CrossRef] [PubMed]

81. Drion, I.; Pameijer, L.R.; van Dijk, P.R.; Groenier, K.H.; Kleefstra, N.; Bilo, H.J. The effects of a mobile phone application on quality of life in patients with type 1 diabetes mellitus: A randomized controlled trial. J. Diabetes Sci. Technol. 2015, 9, 1086-1091. [CrossRef] [PubMed]

82. Harrison, S.; Stadler, M.; Ismail, K.; Amiel, S.; Herrmann-Werner, A. Are patients with diabetes mellitus satisfied with technologies used to assist with diabetes management and coping: A structured review. Diabetes Technol. Ther. 2014, 16, 771-783. [CrossRef] [PubMed]

(C) 2016 by the authors; licensee MDPI, Basel, Switzerland. This article is an open access article distributed under the terms and conditions of the Creative Commons Attribution (CC-BY) license (http://creativecommons.org/licenses/by/4.0/). 